\title{
If the Objective is Herd Immunity, on Whom Should it be Built?
}

\section{Christian Gollier ${ }^{1}$}

Accepted: 11 July 2020 / Published online: 11 August 2020

(c) Springer Nature B.V. 2020

\begin{abstract}
Assuming that there is no other solution than herd immunity in front of the current pandemic, on which groups of citizens should we build this herd immunity? Given the fact that young people face a mortality rate which is at least a thousand times smaller than people aged 70 years and more, there is a simple rational to build it on these younger generations. The transfer of some mortality risk from the elderly to younger people raises difficult ethical issues. However, none of the familiar moral or operational guidelines (equality of rights, VSL, QALY, ...) that have been used in the Western world over the last century weights the value of young lives 1000 times or more than the lives of the elders. This suggests that Society could offer covid protection to the elders by recommending them to remain confined as long as this herd immunity has not been attained by the younger generations. This would be a potent demonstration of intergenerational solidarity towards the most vulnerable people in our community. The welfare gain of this age-specific deconfinement strategy is huge, as it can reduce the global death toll by more than $80 \%$ as compared to a strategy of non-targeted herd immunity.
\end{abstract}

Keywords VSL $\cdot$ QALY · Covid · Pandemics $\cdot$ Herd immunity $\cdot$ Deconfinement

\section{Introduction}

How should we win the war against the covid pandemic? In the absence of a treatment or a vaccine, there exists only two options. The first option is a long confinement of a large fraction of the population that would maintain the reproduction number $\mathrm{R}$ below unity for a very long period of time to obliterate the virus. The economic cost of this suppression strategy is now considered as unbearable in many countries (Miclo et al. 2020). The other option is to progressively build herd immunity by gradually exposing the population to the virus. Under this scenario, the containment is weakened to allow $\mathrm{R}$ to grow above 1 , but not to far away from it to escape the risk of overwhelming hospitals. Whether this is obtained through fine tuning the intensity of the confinement in real time (Alvarez et al.

Christian Gollier

christian.gollier@tse-fr.eu

1 Toulouse School of Economics, University of Toulouse-Capitole, Toulouse, France 
2020; Acemoglu et al. 2020; Pollinger 2020) or through a stop-and-go policy remains to be decided.

In this paper, I suppose that herd immunity is the escape route from the pandemic. In the absence of a vaccine, attaining herd immunity requires exposing a fraction of the population to the virus, and to recognize that some people in this targeted population will die. Determining who should be exposed to the virus to attain the herd immunity is a crucial policy issue. Which criteria should be used to perform this task? Should we leave nature do its dismal work at random until natural immunity is obtained, or should we protect some specific communities from this danger? Two issues, one on efficiency and the other on ethics, are at stake here. Consider first the now well-documented fact that some categories of people are more likely than others to die if exposed to the virus. Some individual characteristics such as the age or the existence of co-morbidities have been shown to have a huge influence on the lethality of SARS-Cov-2. For example, Ferguson (2020) report that the covid infection-fatality ratio is $0.002 \%$ for individuals less than 10 years old, and $9.3 \%$ for people aged 80 years and more. Given this 4650 -fold difference in mortality risk, it may be desirable to expose less vulnerable people first in the hope of building herd immunity before relaxing the protection of the more vulnerable people.

A few recent papers have supported an age-targeted deconfinement strategy. Acemoglu et al. (2020) characterize two intertemporally optimal exit strategies from lockdown, one in which the policy is constrained to be uniform across age classes, and the other in which different age classes are treated in a discriminated way. They claim that 2.7 million lives could be saved in the United States by maintaining a stricter confinement for the seniors. Favero et al. (2020) compare different age-specific policies for Italy and come to the same conclusion of the overwhelming dominance of confining elderly people longer than younger generations. Brotherhood et al. (2020) explore the impact of various confinement policies on the incentive of different age classes to behave efficiently.

Transferring some mortality risk across individuals raises complex moral issues. And discriminating the right to a safe life also raises constitutional concerns. The equality of rights, for example the equal right to the protection from a virus, is a dominant mode of Western ethical principles. The American Declaration of Independence holds the notion that "all men are created equal" to be self-evident. The French Declaration of the Rights of Man and of the Citizen states that "men are born and remain free and equal in rights". And the WHO Constitution (1946) envisages "the highest attainable standard of health as a fundamental right of every human being." But in practice, the right to a safe life has always been vastly discriminated in the Free World. Some people are more exposed to deadly pollutants than others. The access to efficient health services is very heterogeneous across different localities within the same country. Rather than considering health protection as a basic human right, the practice of public decision-making has been to allow for tradeoffs between individual health and collective wealth. Standard guidelines for public benefit-cost analysis most often require to use a specific system of values to account for the impact of public policies on mortality risks. This value system has routinely discriminated against specific individual characteristics such as age and morbidity. Thus, transferring some mortality risk to less vulnerable people may not be socially desirable if society values the lives of these less vulnerable people more. This may be the case for example if vulnerability is positively correlated with age, because preserving the life of a young person is commonly considered as more valuable than preserving the life of an older person. In this paper, I use the existing statistics of covid mortality rates for different age classes to determine the optimal targeted deconfinement for the most common ethical attitudes towards the preservation of different lives. 
An important ethical issue when transferring health risks is related to the interaction of health and wealth (Gollier 2019). Less vulnerable people who could bear more mortality risk may also be poorer or more discriminated in society. Collective inequality aversion justifies valuing mortality risk prevention of poor individuals more than of richer ones. In the case of covid, younger individuals are also poorer on average, which is an argument to limit the mortality risk transfer to them. ${ }^{1}$ Race is also a source of concern, in particular in the U.S., since black people appear to be more vulnerable to the virus, and are also poorer on average. These are important ethical issues that should be solved by considering a multidimensional approach to the apportionment of the covid mortality risk. In this paper, I limit the analysis to the age dimension, the only one on which we have precise statistical information as a covid risk factor.

I don't have a solution to break the moral dilemma of the covid mortality risk apportionment in the general context. My aim in this paper is to quantify the consequences of different social norms used in the current context, as measured by the number of people who are expected to die, or by the number of life years lost. It is sad that democracies have rarely organized a public debate about how tradeoffs between health and wealth should be made at the collective level. The absence of democratic legitimacy attached to the competing value systems to perform this task creates a vacuum for decision-makers. The good news from my analysis is that all familiar value systems lead to the same conclusion in the context of the covid pandemic.

\section{The Model}

The population is composed of $I$ individuals. Individual $i \in\{1, \ldots, I\}$ has a probability $p_{i}$ of dying conditional on being infected. Society associates a value $v_{i}$ to changes in the survival probability of that individual. ${ }^{2}$ Let $x_{i}$ take value 1 if individual $i$ is exposed to the virus and 0 if that individual is preserved from this exposure. Let $\pi$ denote the proportion of the population that must be exposed to the virus. I characterize the strategy $X=\left\{x_{1}, \ldots, x_{I}\right\}$ that minimizes the aggregate value of lives lost under the constraint of attaining the proportion $\pi$ of exposure to the virus ${ }^{3}$ :

$$
\min _{\left\{x_{1}, \ldots, x_{I}\right\} \in\{0,1\}^{I}} \sum_{i=1}^{I} x_{i} p_{i} v_{i} \quad \text { s.t. } \sum_{i=1}^{I} x_{i} \geq \pi I .
$$

Let me reinterpret this program in the context of the current covid pandemic. To better understand this reinterpretation, keep in mind that the asymptotic proportion of recovered people of a pandemic is less than unity and is positively related to the reproduction number $\mathrm{R}$. Keep also in mind that $\mathrm{R}$ is a function of the intensity of social interactions, and thus

\footnotetext{
1 A similar argument can be made in the context of climate change. Notice however that in that context, wealth differences across generations are taken into account by using a positive discount rate to value the social cost of carbon. Future generations are typically assumed to be wealthier in expectation. The Ramsey rule implies a positive discount rate in that case.

${ }^{2}$ In the different policies that I consider, the changes in mortality risk faced by different age classes remain moderate, so that $v_{i}$ can be interpreted as the Value of Statistical Life (VSL), a concept that values marginal changes in the probability to die.

3 In other words, I adopt a cost-efficiency approach. Contrary to the cost-benefit approach, I don't arbitrage here between health and wealth.
} 
of the public policy intended to reduce it. Thus, the weaker the social distancing policy in a community, the larger the number of people who are immune in the steady state in that community. ${ }^{4}$ Now, let a first group of individuals be selected to be deconfined with the smallest restrictions in terms of social distancing compatible with the capacity of ICUs in the country. Let this subpopulation create their own herd immunity. The proportion of individuals who are immune in this subpopulation at the end of the contagion process is large because of the importance of social interactions in this first period. During this period, the second group of individuals is protected from physical contacts with the first group. Once the high proportion of immunized people in the first group is obtained, the second group is deconfined and some light prevention rules, such as bearing face masks or teleworking for productive activities that can be done in distance without impacting productivity, are established to make sure that the proportion of immunized people in the whole population is larger than the new herd immunity proportion given these light restrictions. ${ }^{5}$ An illustration of this dynamic policy is described by Favero et al. (2020) and Gollier (2020) for example. This dynamics may be complex, and this complexity may hide the crucial moral and economic issues behind the recommendations that can be extracted from its type of analysis. The bottom line of any individual characteristic-specific deconfinement strategy is that some classes of individuals will contribute more than others to building herd immunity. Program (1) describes in its simplest form the key issues behind the political choice of deconfinement. Remember that refusing any discrimination in the deconfinement strategy is a decision in itself.

The solution of program (1) is trivial. The decision-maker must select a threshold $\lambda$ such that all individuals $i$ with a score $p_{i} v_{i}$ smaller than $\lambda$ are exposed and all the other are protected. The threshold $\lambda$ is selected so that this decision rule leads to having a proportion $\pi$ of the population being exposed and therefore developing immunity.

In this paper, I focus on age-specific deconfinement strategies. ${ }^{6}$ This is because age is a key individual characteristic that simultaneously affects the lethality of the virus and the societal value of lives saved. In the case of France, Salje et al. (2020) from Institut Pasteur have estimated the infection fatality proportion (IFP) by age, using French data available in mid-April. This estimation of the $p_{i}$ is documented in Table 1. In France, $80 \%$ of the covid death toll is accounted for by individuals aged 66 years or older. Ferguson (2020) documents age-differences of the IFP estimations exhibiting the same order of magnitude, using international data available in mid-March.

I also assume that the post-pandemic herd immunity proportion is $\pi=80 \%$. In reality, this proportion remains uncertain, and is sensitive to the intensity of social interactions.

\footnotetext{
${ }^{4}$ Pindyck (2020) characterizes the relationship between the herd immunity proportion and the social distancing proportion.

5 Technically, let $n_{1}$ and $n_{2}$ denote the size of the two groups, respectively the unlocked one and the confined one. Let $x$ denote the asymptotic proportion of recovered people in a community without social restriction. We assume that after deconfining the second group, some light social restrictions are imposed, yielding an asymptotic immunity proportion $X$, with $X<x$. The intensity of these restrictions is selected in such a way that $X=n_{1} x /\left(n_{1}+n_{2}\right)$. In other words, when unlocking the second group with the new social restriction, the proportion of immune people in the population is equal to $X$, so that no second wave occurs.

${ }^{6}$ Other risk factors such as obesity, diabetes and gender also matter. I prefer to focus on age, as it is probably less controversial. See my discussion in Sect. 4 .
} 
Table 1 Estimation of the IFP by age class in France. Source: Salje et al. (2020) and INSEE

\begin{tabular}{lll}
\hline Age class & Population size & $\begin{array}{l}\text { Infection fatality } \\
\text { proportion }\left(p_{i}\right)(\%)\end{array}$ \\
\hline $0-19$ & $16,084,743$ & 0.001 \\
$20-29$ & $7,470,908$ & 0.007 \\
$30-39$ & $8,288,257$ & 0.02 \\
$40-49$ & $8,584,449$ & 0.05 \\
$50-59$ & $8,785,106$ & 0.2 \\
$60-69$ & $7,999,606$ & 0.8 \\
$70-79$ & $5,693,660$ & 2.2 \\
$80+$ & $4,156,974$ & 8.3 \\
\hline
\end{tabular}

\section{Efficient Age-Specific Deconfinement Strategies}

\subsection{Equality}

In most countries, the evolution of the pandemic is measured by the cumulative number of individuals who died from the virus. This is how politicians, the media and the citizens follows the evolution of the pandemic. This suggests a normative approach in which mortality risk is valued independent of the age of the victims: $v_{i}=1$ for all $i \in\{1, \ldots, I\}$. It translates the ethical/constitutional concept of the equality into a value system.

Many life-saving regulations affect mortality risks across a wide population and result in a small change in risk at the individual level. Public administrations routinely evaluate the net social benefit of these policies. In France, the Quinet Report (Quinet 2013) argues in favor of valuing changes in mortality risk independent of age to evaluate public policies and investments. In the United States, the Office of Management and Budget and the Environmental Protection Agency (EPA) have been recommending and using an age-independent life valuation approach over many decades (US-EPA 2010): "The committee concluded that the existing economics literature does not provide clear theoretical or empirical support for using different values for mortality risk reductions for differently-aged adults". As explained by Robinson (2007) and Viscusi (2009), this decision has been very controversial. In 2008, the EPA produced a report evaluating the Clear Skies initiative, it used a constant value of statistical life, but it also examined an alternative measure of the policy containing a 37\% discount VSL for people aged 65 or over. Elderly citizen groups launched a series of public protests against what has come to be known as the "senior discount" or the "senior death discount". Since then, the EPA has abandoned the age-adjustment of the VSL.

When comparing different exit strategies of the current pandemic, Favero et al. (2020) also value lives lost without differentiating victims by age. Notice that I do not monetize lives in this paper. Choosing a $v_{i}=v$ of 3 million or 10 million euros is irrelevant for the analysis. Rather, it is the relative value of life across age classes which matters.

Using Table 1 , the equality score $p_{i} v_{i}=p_{i} v$ is increasing with age. Under this familiar ethical norm, the efficient strategy consists in determining a age threshold $A$ such as all individuals aged less than $A$ are deconfined, whereas all those aged more than $A$ remain confined until herd immunity is obtained. Because $20 \%$ of the population is older than 65 years, this means that the deconfinement should be limited to people less than 65 years old. 
Table 2 Infected-fatality proportion, quality-adjusted life expectation and QALE score by age class. Source: LoveKoh et al. (2015), and own computation

\begin{tabular}{|c|c|c|c|}
\hline Age class & $\begin{array}{l}\text { IFP } \\
p_{i}(\%)\end{array}$ & $\begin{array}{l}\text { QALE value } \\
v_{i}\end{array}$ & $\begin{array}{l}\text { QALE score } \\
p_{i} v_{i}\end{array}$ \\
\hline 0-19 & 0.001 & 63.0 & 0.1 \\
\hline 20-29 & 0.007 & 49.5 & 0.3 \\
\hline 30-39 & 0.02 & 40.6 & 0.8 \\
\hline $40-49$ & 0.05 & 32.1 & 1.6 \\
\hline $50-59$ & 0.2 & 24.2 & 4.8 \\
\hline $60-69$ & 0.8 & 17.0 & 13.6 \\
\hline 70-79 & 2.2 & 11.0 & 24.2 \\
\hline $80+$ & 8.3 & 5.8 & 47.8 \\
\hline
\end{tabular}

\subsection{Quality-Adjusted Life Expectancy}

A more recent tradition in health economics is to value each year of life lost adjusted for its health quality. It combines individual information on mortality and morbidity. As one grows older, the expected number of years that a person has left to live declines. Similarly, morbidity increases. Taken together, the quality adjusted life expectation (QALE) of an individual is lower the older the person. It is an aggregate version of the quality-adjusted life year (QALY). This relation between QALE and age has been measured by Love-Koh et al. (2015) for the United Kingdom, and is documented in Table 2.

Suppose that the social planner considers that QALE is the morally acceptable way to value lives lost in the face of the covid crisis, i.e., $v_{i}=Q A L E_{i}$ for all age classes $i$. Under this assumption, the social planner will for example value the life of a 20-29 years old person 4.5 times more than the life of a 70-79 years old person. Compared to the equalityof-rights criterion, the QALE criterion puts more weight to the survival of young people. It thus has the potential to reverse the recommendation to expose young people first. This would be the case if the growth rate of the mortality rate with age is smaller than the reduction rate of QALE with age. As shown in the last column of Table 2, this is not the case overall, $p_{i} v_{i}$ is an increasing function of age. The QALE and equality criteria generate the same recommendation to limit the exposure to the virus to just people younger than 65 .

Because the quality-adjustment contained in the QALE measures favors younger people, there is no doubt that a non-quality-adjusted life expectancy criterion, such as the value of statistical life year (VSLY), will generate the same recommendation to deconfine younger generations first.

\subsection{Revealed Preference}

Economists have long pursued the goal of measuring how people value their own mortality risk. This has been made possible by the development of the concept of the value of statistical life (VSL), by Drèze (1962), Schelling (1968) and Jones-Lee (1974). A large literature has been built over the last half century to measure how mortality differentials affects wages and real estate prices for example. Some RP studies estimate willingness to pay from market prices for products (such as airbags) that reduce the likelihood of a fatal injury. This yields estimates of the revealed preference (RP) valuation of statistical lives. A subset of these studies have documented the fact that these estimates are sensitive to the 
Table 3 Revealed preference life valuation and RP score by age class. Source: Greenstone and Nigam (2020), and own computation

\begin{tabular}{lcc}
\hline Age class & RP value $\left(v_{i}\right)$ & RP score $\left(p_{i} v_{i}\right)$ \\
\hline $0-19$ & 15.0 & 0.01 \\
$20-29$ & 16.1 & 0.11 \\
$30-39$ & 15.8 & 0.32 \\
$40-49$ & 13.8 & 0.69 \\
$50-59$ & 10.3 & 2.06 \\
$60-69$ & 6.7 & 5.36 \\
$70-79$ & 3.7 & 8.14 \\
$80+$ & 1.5 & 12.45 \\
\hline
\end{tabular}

age of the person facing the mortality risk. The law of one price suggests that the social planner should use the same system of values as the one used by citizens to perform policy evaluations. Murphy and Topel (2006) have calibrated an age-dependent VSL function by using revealed preference studies to evaluate the social benefit of improved life expectancies over the last century. Greenstone and Nigam (2020) have used the age-specific life values of Murphy and Topel to estimate the net benefit of the confinement strategy in the face of the current pandemic. I report these RP values by age class in Table 3 . The value weight of the RP approach has an inverted-U shape, where the value of life first slightly increases with age, peaks in the twenties, and then declines. ${ }^{7}$

As in the QALE approach, the reduction of the value $v_{i}=R P_{i}$ with age $i$ is too small to compensate for the large growth rate of the mortality risk, so that the RP score $p_{i} R P_{i}$ is increasing with age. Here again, the efficient strategy is to first expose people aged less than 65 years old.

\subsection{Stated Preference}

In the context of mortality risk, the stated preference (SP) approach involves asking members of a representative sample of the population at risk about their WTP for a small hypothetical improvement in their survival probability. In some studies, they are asked to take the role of the social planner in determining the best choice in a set of options involving different numbers of individuals of different ages facing an increased mortality risk. In the covid context, Landier (2020) confront respondents to two possible allocations of ventilators, one for retirement homes in which 50,000 lives of patients aged 70 years and older will be saved, and the other in hospitals in which 30,000 lives of patients aged 30 years and older will be saved. Twenty-eight percent of the respondents expressed a preference for saving the larger number of patients in retirement homes. Carlsson et al. (2010) provide more information about the differential valuation of life of different ages. In the context of car or fire casualties, they found that avoiding the fatality of one 5-15-year-old person is equivalent to avoiding 1.4 fatalities of 35-45-year-old people and to avoiding 3.3 fatalities

\footnotetext{
7 Shepard and Zeckhauser (1984) also estimates an inverted-U shaped age-sensitive VSL by using a lifecycle income and consumption model with a mortality risk. Their VSL starts at 500,000 at age 20 to peak at $1,250,000$ at age 40 , and declines to 630,000 at age 60 , in USD of 1978 . This may be due to a time-consistency problem. Under this valuation system, protecting the seniors is optimal too.
} 
Table 4 Stated preference life valuation and SP score by age class. Source: Carlsson et al. (2010), and own computation

\begin{tabular}{lll}
\hline Age class & SP value $\left(v_{i}\right)$ & SP score $\left(p_{i} v_{i}\right)$ \\
\hline $0-19$ & 1 & 0.001 \\
$20-29$ & 0.857 & 0.006 \\
$30-39$ & 0.762 & 0.015 \\
$40-49$ & 0.646 & 0.032 \\
$50-59$ & 0.509 & 0.102 \\
$60-69$ & 0.372 & 0.298 \\
$70-79$ & 0.234 & 0.515 \\
$80+$ & 0.097 & 0.805 \\
\hline
\end{tabular}

of 65-75-year-old people. A linear interpolation of this SP valuation system is represented in Table 4.

Because the SP-score is increasing with age, the stated preference criterion is also compatible with prioritizing the protection of the elderly in spite of their relatively lower stated value.

\section{Discussion}

The preliminary conclusion from the previous section is that whatever the familiar moral principles to be used to perform the policy analysis, it is optimal to protect the older generation from exposure to the virus. This is because the growth of the mortality risk with age is so large that there exists no reasonable valuation weights by age class that can reverse the intuition that the most vulnerable people must be protected. Their lower life expectancy does not justify a choice reversal. In spite of this evidence, most countries are contemplating a deconfinement strategy which is not discriminated by age. It is thus useful to compare this observed policy with the optimal strategy. I illustrate this for the case of France.

Suppose that herd immunity can be obtained with an immunity rate of $80 \%$. The observed policy of a non-discriminated deconfinement implies that all age classes will face a $80 \%$ rate of infection, implying in turn a death count corresponding to their age-specific mortality rate. ${ }^{8}$ This is documented in the second column of Table 5 and by the dashed curve in Fig. 1. On the contrary, given the demographic characteristics of France, the optimal strategy consists in deconfining all people aged 65 and younger (in fact $100 \%$ of the 0-59 age class, and $55.47 \%$ of the 60-69 age class). Remember that I assume that there is an acceptable confinement technology that fully protects the elderly from the virus, so that no death occurs among the elders. In reality, the confinement will be imperfect, but I don't take account of this imperfection in my analysis. I also document fatalities by age class under the optimal policy in Table 5 and in Fig. 1.

Attaining the herd immunity under total deconfinement will impose 446,792 deaths, mostly for people older than 60 years. This must be compared to the death of 59,704 persons under the optimal age-specific deconfinement strategy. The optimal policy would

\footnotetext{
${ }^{8}$ In reality, the social interaction matrix is not uniform, and old people have less interaction with others. This implies that their susceptibility ratio will asymptotically converge to a larger ratio than for younger generations. I don't take account of this dynamic effect in this analysis.
} 
Table 5 Estimated death toll and loss in quality-adjusted life expectation by age class for the total and optimal deconfinement

\begin{tabular}{lcccc}
\hline Age class & $\begin{array}{l}\text { Deaths in total } \\
\text { deconfinement }\end{array}$ & $\begin{array}{l}\text { Deaths in optimal } \\
\text { deconfinement }\end{array}$ & $\Delta$ Deaths & QALE lost (in years) \\
\hline $0-19$ & 129 & 161 & 32 & 2,026 \\
$20-29$ & 418 & 523 & 105 & 5147 \\
$30-39$ & 1326 & 1658 & 332 & 13,445 \\
$40-49$ & 3434 & 4292 & 858 & 27,542 \\
$50-59$ & 14,056 & 17,570 & 3514 & 85,115 \\
$60-69$ & 51,197 & 35,500 & $-15,697$ & $-266,511$ \\
$70-79$ & 100,208 & 0 & $-100,208$ & $-1,103,033$ \\
$80+$ & 276,023 & 0 & $-276,023$ & $-1,590,290$ \\
Total & 446,792 & 59,704 & $-387,088$ & $-2,826,533$ \\
\hline
\end{tabular}

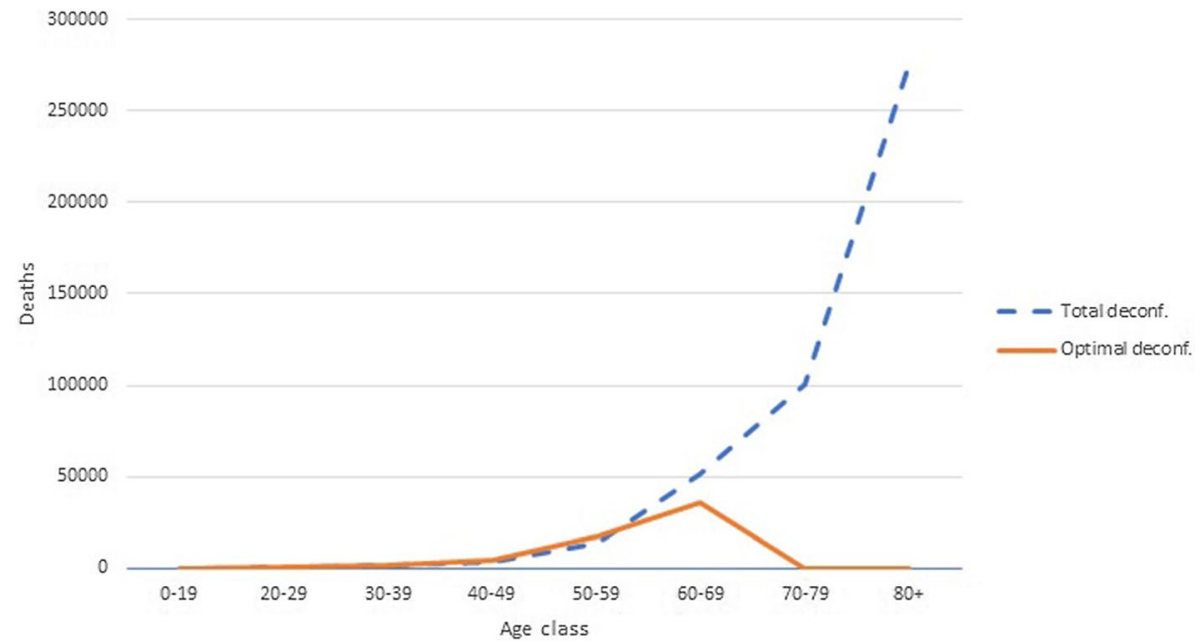

Fig. 1 Number of deaths by age class

thus save 387,088 lives. Almost 3 million quality-adjusted life years would be saved under the optimal policy. In this study, I discriminate the deconfinement strategy only based on age. But we know now that comorbidities have a large impact on the mortality rate too. For example, in New York state, just over $86 \%$ of the 5489 reported COVID-19 deaths before 6 April 2020 involved at least one comorbidity, according to the state's department of health..$^{9}$ Adding some of these comorbidities such as diabetes $(37.3 \%$ of the New York deaths) and obesity in the individual characteristics of the discriminated deconfinement strategy could considerably reduce the death toll of this strategy, compared to what is described in Table 5.

\footnotetext{
${ }^{9}$ https://www.the-hospitalist.org/hospitalist/article/220457/coronavirus-updates/comorbidities-rule-newyorks-covid-19-deaths.
} 
The ethical issue is that the benefit of the optimal policy implies a transfer of the mortality risk from the elders to the younger generations. For example, 32 more individuals below the age of 20 years will die in France under the optimal policy compared to the nondiscriminated policy, but the optimal policy will save 276,023 people aged 80 or more. But because the utility loss from dying is larger for the young than for the old, the utilitarian norm (Adler 2019) favors this transfer only if this valuation difference is not too large. A prioritarian norm gives even greater weight to individuals with lower lifetime utility, but for reasonable parameter values explored by Adler et al. (2019), it is unlikely to reverse the policy recommendation. One position that could oppose the policy recommendation is the "fair innings" argument introduced by Harris (1985, p. 91) : "The fair innings argument requires that everyone be given an equal chance to have a fair innings, to reach the appropriate threshold but, having reached it, they have received their entitlement. The rest of their life is the sort of bonus which may be canceled when this is necessary to help others reach the threshold." Taken literally, this argument, like the Rawlsian maxmin criterion, implies a lexicographic priority for the young by rejecting any transfer of mortality risk from old (who have reached their fair innings) to young.

In this paper, I assume that sick people who recover from the virus bear no long-term consequence of having been exposed to it. As I write this last version of the paper, it is a source of concern that this assumption may be wrong. A radical revision of the recommendations described here will have to be undertaken if recovered people develop comorbidities. If the assumption is wrong, then the existence of irreversible adverse health effects would be an argument to protect the young generations, and a finer benefit-cost analysis would have to be performed. As stated by my anonymous reviewer, "to the extent that catching covid means people suffer for life, then there may be good reason to not target the young".

Does the discriminated deconfinement strategy require a restriction of freedom? This pandemic entails an obvious externality issue, since the risky behavior of some people affects the risk borne by others. Implementing a Pigouvian tax solution is not operationally viable. At the individual level, exiting the confinement has a cost and a benefit. The cost is the increased mortality risk. The benefit is psychological, social and financial. For the senior who should stay confined under the socially optimal strategy, I believe that it would be individually rational for them to remain confined. The deconfinement of the younger generations will generate a new wave of infection - this is indeed the objective - that will transform the country into a highly lethal environment for the seniors, for a period of 2 or 3 months. If a person aged 80 exits confinement, her probability of being infected would equal $80 \%$, with a mortality rate of $8.3 \%$. If her own VSL is 1 million euros, her own valuation of this increased mortality risk is 66,400 euros. I believe that her willingness to pay to eliminate the social and psychological stress of the 3-month confinement is much smaller than that, thereby supporting the rationality of the self-confinement of senior people. However, limited rationality may be a problem here, in particular if it implies a surge in demand for face masks. This could be countered by alleviating the burden of the confinement. On-line networking could be boosted in retirement home, together with "happy hours" in shops. Free access could be offered to virus-free spaces in theaters and concert halls, and in nice (currently empty) hotels along our beaches for example. Some testing capacity could also be targeted to visitors in retirement homes that are most closely related to their senior guests. 
What about the mortality risk borne by the younger generations? As their attitude to the lockdown has been quite negative, the risk that they will bear in the period of herd immunity building can be borne on a voluntary basis. ${ }^{10}$ This limits the ethical issue of the proposed transfer of mortality risk. Moreover, the additional mortality risk for the young is quite limited compared to other health risks faced by this age class. For example, the proposed age-specific deconfinement strategy examined in this paper generates 32 more covid victims aged 20 or less. This should be compared to 500+ (562 in 2017) young people who die in car accidents every year in France.

Then, why do most States refuse to consider a discriminated deconfinement strategy? People are often reluctant to play an active role in decisions involving important moral issues. Moral psychologists have long been studying when people find it acceptable to sacrifice one life to save other lives. Awad et al. (2020) have revisited the well-known "trolley problem" in which one must rank two scenarios. In the "switch scenario", a trolley is about to kill five workers, but can be redirected to a different track, in which case it will kill one worker. In the "footbridge scenario", a man can be pushed in front of the trolley. This man will die, but his body will stop the trolley before it can kill the five workers on the track. In this second scenario, the decision-maker must take a more active and visible role in the death of the victim by pushing him on the trolley track. In all cultures, this footbridge scenario is considered as much less acceptable, probably for that reason. Landier (2020) make a similar observation in the context of the current pandemic. When confronting survey respondents to the question of whether to offer a single ICU to one of two sick people, one with a larger chance of survival than the other, $37 \%$ of the respondents prefer allocating the ICU by using the first-come-first-served rule. When exposing one age group of the population to build the herd immunity in order to protect another age group, this decision reallocates the mortality risk across individuals in a similar fashion than in the ICU story. The reluctance to take active decisions aiming at reallocating mortality risk across different classes of citizens is an important bias in collective decision making that one should address during this pandemic. ${ }^{11}$ It goes against the standard public decision-making rules used in normal times in most western countries for at least 50 years. This bias may have catastrophic consequences in the final death toll, as shown in Table 5.

\section{Conclusion}

Most parameters of the dynamics of the covid-19 pandemics are still surrounded by deep uncertainties, and different countries have been following different strategies in the face of this situation. It will be a long time before one will be able to determine which is the winning strategy. Many governments have implemented a Plan A aimed at obliterating the coronavirus, far from herd immunity. This requires maintaining the reproduction number $\mathrm{R}$ low enough for a relatively long period of time, potentially until a vaccine is found, or until the last clusters of the virus can be eradicated through an aggressive testing-and-tracing

\footnotetext{
${ }^{10}$ Let's for example consider a 30 -year old person. Her covid mortality risk is $80 \%$ of $0.02 \%$. Using a VSL of 3 million euros, her covid mortality cost is estimated at 480 euros, which is likely to be much smaller than the social, psychological and financial benefit of her deconfinement.

11 In decision theory, there exists an argument for people having a preference for reducing the choice set based on regret aversion. Having no choice eliminates the risk of regret. See for example Sarver (2008) and Gollier (2018).
} 
policy. The economic cost of this suppression strategy may be large, and its success may be far from certain, in particular when other regions of the world follow other strategies. In the absence of treatment or vaccine, there exists only one possible plan, herd immunity. I examined this Plan B in this paper. One key problem with Plan B is the unbearable life cost of the non-discriminated deconfinement strategy typically considered to attain herd immunity. Under the assumptions of an average $1 \%$ mortality rate and of a herd immunity with an asymptotic $80 \%$ rate of immunity, one should expect that $0.8 \%$ of the population will succumb in the long run.

However, this problem has a solution. It consists in building the herd immunity with the categories of the population which are the least likely to die if infected. Given the huge differences in mortality rates across age classes, this herd immunity should be built by deconfining the younger generations first. This strategy implies an increased mortality risk for these less vulnerable people, which is ethically questionable. However, because transferring the exposure from the old to the young reduces the death probability by a factor 1000 , moral concerns could reverse this recommendation only if society values one young life more than a thousand lives of people aged 65 years or more. This would go against several decades of policy evaluation practice in which all lives are equally valued, or in which years of life lost are counted. It also goes against observed individual preferences related to mortality risk, either revealed or stated.

Acknowledgements I thank Ingela Alger, Jim Hammitt, Ulrich Hege, Paul Seabright, Nicolas Treich and an anonymous reviewer for helpful comments. The research leading to these results has received the support from the ANR Grants Covid-Metrics and ANR-17-EURE-0010 (Investissements d'Avenir program).

\section{References}

Acemoglu D, Chernozhukov V, Werning I, Whinston M (2020) A multi-risk SIR model with optimally targeted lockdown. NBER WP 27102

Adler MD (2019) Measuring social welfare: an introduction. Oxford University Press, Oxford

Adler MD, Ferranna M, Hammitt JK, Treich N (2019) Fair innings: the utilitarian and prioritarian value of risk reduction over a whole lifetime. Duke Law School Public Law and Legal Theory Series No. 2019-79

Alvarez F, Argente D, Lippi F (2020) A simple planning problem for COVID-19 lockdown. COVID Econ $14: 1-29$

Awad E, Dsouza S, Shariff A, Rahwan I, Bonnefon JF (2020) Universals and variations in moral decisions made in 42 countries by 70,000 participants. Proc Natl Acad Sci 117(5):2332-2337

Brotherhood L, Kircher P, Santos C, Tertilt M (2020) An economic model of covid-19 epidemic: the importance of testing and age-specific policies. Mimeo, New York

Carlsson F, Daruvala D, Jaldell H (2010) Preferences for lives, injuries, and age: a stated preference survey. Accid Anal Prev 42:1814-1821

Drèze J (1962) L'utilité sociale d'une vie humaine. Rev Fr Rech Opér 23:93-118

Favero C, Ichino A, Rustichini A (2020) Restarting the economy while saving lives under covid-19. WP Bocconi University, Milan

Ferguson NM et al (2020) Impact of non-pharmaceutical interventions (npis) to reduce covid- 19 mortality and healthcare demand. CEPR Covid Econ 2:60-66

Gollier C (2018) Aversion to risk of regret and preference for positively skewed risks. Econ Theory. https:// doi.org/10.1007/s00199-018-1154-4

Gollier C (2019) A general theory of risk apportionment. Mimeo, New York

Gollier C (2020) Cost-benefit analysis of age-specific deconfinement strategies. COVID Econ 24:1-31

Greenstone M, Nigam V (2020) Does social distancing matter? CEPR Covid Econ 7:1-22

Harris J (1985) The value of life. Routledge and Kegan Paul, London

Jones-Lee M (1974) The value of changes in the probability of death and injury. J Polit Econ 82:835-849

Landier A, Sastry P, Sraer D, Thesmar D (2020) Moral tradeoffs in the covid crisis. Mimeo, New York 
Love-Koh J, Asaria M, Cookson R, Griffin S (2015) The social distribution of health: estimating qualityadjusted life expectancy in England. Value Health 18:655-662

Miclo L, Spiro D, Weibull J (2020) Optimal epidemic suppression under an ICU constraint. Mimeo, New York

Murphy KM, Topel RH (2006) The value of health and longevity. J Polit Econ 114:871-904

Pindyck RS (2020) Covid-19 and the welfare effects of reducing contagion. Mimeo, New York

Pollinger S (2020) Optimal tracing and social distancing policies to suppress COVID-19. COVID Econ 23:152-187

Quinet E (2013) L'évaluation socioéconomique des investissements publics. Commissariat Général à la Stratégie et à la Prospective, Paris

Robinson LA (2007) How US government agencies value mortality risk reductions. Rev Environ Econ Policy 1:283-299

Salje H, Tran Kiem C, Lefrancq N, Courtejoie N, Bosetti P et al. (2020) Estimating the burden of SARSCoV-2 in France. pasteur-02548181

Sarver T (2008) Anticipating regret: why fewer options may be better. Econometrica 76:263-305

Schelling T (1968) The life you save may be your own. In: Chase SB (ed) Problems in public expenditure analysis. The Brookings Institution, Washington, D.C., pp 127-162

Shepard DS, Zeckhauser RJ (1984) Survival versus consumption. Manag Sci 30:423-39

US-EPA (2010) Valuing mortality risk reductions for environmental policy: a white paper. SAB-EEAC Review Report

Viscusi WK (2009) The devaluation of life. Regul Gov 3:103-127

Publisher's Note Springer Nature remains neutral with regard to jurisdictional claims in published maps and institutional affiliations. 